\section{Military Technical College Kobry El-Kobbah, Cairo, Egypt.}

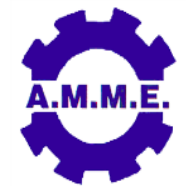

$18^{\text {th }}$ International Conference on Applied Mechanics and Mechanical Engineering.

\title{
SURFACE ROUGHNESS JUSTIFICATION IN ADDITIVE MANUFACTURING
}

\author{
M. Hamoud ${ }^{*}$
}

\begin{abstract}
Recently, developing Additive Manufacturing (AM) technologies have been increased, because its advantages toward the rapid manufacturing of physical model from the CAD system. In the AM area, the designer specifies the desired surface quality on the working drawing to be considered during the building operation. The produced surface depends on the building parameters. The aim of this work is to develop new empirical models for predicting the building orientation that satisfy required surface roughness based on FDM m/c. In this study, a new 3D CAD specimen was proposed to decrease the number of experiments, measuring errors and building cost. The specimen contains the surface orientation from $0^{\circ}$ to $90^{\circ}$ with step $10^{\circ}$ that was built three times at three different layer thickness $(0.1,0.3$, and $0.4 \mathrm{~mm}$ ). The order of the model was determined by the test of all orientations accept at $30^{\circ}$ and $60^{\circ}$ that was used for model verification. Results show the three prediction models at certain three values of layer thicknesses. The prediction of building orientation has several benefits as follows; it is very useful information for the designer before exporting STL file, the AM users can choose the process parameters without extra trails, increase the opportunity of technology to shear in Rapid Manufacturing (RM), Rapid Tooling (RT), and in medical applications.
\end{abstract}

\section{KEY WORDS}

Additive Manufacturing, Surface Roughness Prediction, Fused Deposition Modeling, Prediction of Building Orientation.

\footnotetext{
* Assistant Professor, Faculty of Engineering, Helwan University, Cairo, Egypt. Email:,Dr_hamoud2015@h-eng.helwan.edu.eg.
} 


\section{NOMENCLATURE}

$\begin{array}{ll}\text { a: } & \text { Polynomial coefficient } \\ \mathrm{F}(\mathrm{x}): & \text { Polynomial function } \\ \text { Lc: } & \text { The cut off length } \\ \text { Ln: } & \text { the evaluation length } \\ \mathrm{Lt}: & \text { Layer thickness }(\mathrm{mm}) \\ \mathrm{n}: & \text { the number of measuring points } \\ \mathrm{O}: & \text { Orientation angle (degree) } \\ \mathrm{Ra}: & \text { the surface roughness value (micron) }\end{array}$

\section{INTRODUCTION}

Additive manufacturing (AM) has drawn interest from fields ranging from aerospace to tissue engineering. It is a collection of versatile technique of AM that allow material design from 3D digital model [1-3]. Synonyms are Solid Free-Form-Fabrication (SFFF), 3D Printing (3DP), Rapid Prototyping (RP) or Layered Manufacturing (LM) technology. 3D CAD data are sliced into multiple 2D layers of a specific thickness. The AM machine manufactures the layers in order to join them together in a layer-bylayer way into the physical part [4]. AM offer various advantages over conventional manufacturing methods as follows; complicated features are possible which are difficult with most conventional manufacturing methods, assembled models, tooling can be produced without any needs to jigs or fixtures [5]. Many process techniques are used including Fused Deposition Modeling (FDM), 3D Printing (3DP), Stereolithography (SLA), Selective Laser Sintering (SLS), and Electron Beam Melting (EBM). All techniques share in the same basic process, which starts with creating of a 3D CAD solid model, converting the CAD model to STL file format, slicing the converted file into $2 \mathrm{D}$ cross-sectional layers, constructing the model and finally postprocessing of the model [6].

In FDM, the thermoplastic material is extruded through a nozzle onto a horizontal build platform (Fig. 1) [7]. The controlled extrusion head deposits very thin beads of material onto the build platform to form the first layer. The platform is maintained at a lower temperature, so that the thermoplastic quickly hardens and welds to the previous layers. After the platform lowers, the extrusion head deposits a second layer upon the first. Again, each layer is built on top of pervious one, commencing at the base of the part. The thermoplastic cools very rapidly to form a solid and this enables overhanging sections on the models to be constructed without supports [8]. An advantage of this system is that it may be viewed as a desktop prototyping facility in a design office since the materials it uses are cheap, non-toxic, non-smelly and environmentally safe. There is also a large range of colures and materials available, such as investment casting wax and ABS plastic. A model material that can be built by FDM technique such as polymers (PP, PC) and thermoplastic such as acrylonitrile butadiene styrene (ABS) [9], support materials such as nylon and investment casting wax. FDM machines are proper for an office environment. Although the advantages of FDM machines, disadvantage of the technique is the producing of rough surfaces. FDM machines have minimum value of layer thickness and arbitrary building orientations that didn't satisfy a designer needs or desired surface roughness. In addition, the minimum layer thickness can produce a part with fine surface quality 
that isn't required for the part. To overcome these problems and achieve a certain surface roughness, a prediction model for building orientation is necessary before the actual building.

\section{LITERATURE RIVIEW}

Surface smoothness is important area studied in AM. Recently, the investigations pay their attention in improving the produced surface roughness which depends on the process parameters such as building orientation and layer thickness during the part building. This section reviews some of the important and relevant aspects improving the surface roughness. Wang et. al. [10] presented a Theoretical and experimental study on surface roughness of $316 \mathrm{~L}$ stainless steel metal parts obtained through selective laser melting. The authors discussed the curved surface roughness briefly; their results showed that the curved surface quality was affected by much more factors than cubic parts. Measured Ra value was about $50 \%$ greater than the theoretical value. The reasons to this difference include the unavoidable deviation between theoretical assumptions and actual experiments, unstable melting track, balling effect and powder adhesion. Vahabli, and Rahmati [11] presented a hybrid model for the analytical estimation of the surface irregularity of the ABS plus model manufactured by FDM. Delfs et al. [12] aimed at prediction of the surface quality in dependence of the part building orientation. The results for the surface quality of a part lead to the general assumption that the part orientation affects the overall part surface roughness. Boschetto et al. [13] predicted the surface irregularity value for FDM parts. This work extended the characterization to all the surface irregularity parameters that achievable by a profilometric investigation. Data were measured and complemented by microscopic analysis. Reeves and Cobb [14] offered a surface roughness prediction for AM to optimize the building orientation in terms of overall surface roughness for given model. Bacchewar et al. [15] concentrated on the SLA technique that is based on the photo-polymerization of liquid resin. Hence, they could express the mean roughness value $(\mathrm{Ra})$ as a function of surface angles only by stair-stepping effect. This distribution was compared with experimental data from surface angles from $0^{\circ}$ to $180^{\circ}$ in three degrees intervals. These measurements were done with parts from SLA, SLS and FDM processes.

These previous study provided good contributions, but they didn't present an analytical technique to choose the building orientation that satisfy the specific surface roughness that assigned in the working drawing. The objective of this paper is presenting regression models based on experimental results to satisfy the production requirements of the produced surface by FDM without extra trials and operator intervention.

\section{EXPERIMENTAL TEST PARTS DESIGN AND BUILD}

To achieve a fabricated part with certain surface roughness, it is required to know how the process parameters would affect the resulting surface roughness. A more desirable way to do this is to develop empirical models based on experimental results, which can be used to decide the building orientation parameter. Therefore, experiments on surface roughness have been conducted, and data was used for 
building the empirical models. The following sub sections will describe the procedure that used to develop the empirical models.

\section{Design of Experiment}

This section describes the technical specifications of the FDM machine used in the experiment and the influence of its parameters on the surface roughness. The FDM machine model is "MakerBot Replicator 2X Experimental" 3D Printer with technical specifications presented in Table 1. Layer thickness and the building orientation are two process parameters that considered in the experiment. The available layer thickness on the machine is varying from 0.1 to $0.4 \mathrm{~mm}$ in step of $0.01 \mathrm{~mm}$. In the other words, there are 30 values of layer thickness available on the machine. The available reorientations of CAD model vary from $0^{\circ}$ (designed surface orientations) to $90^{\circ}$ in step of $1^{\circ}$. In the other words, there are 90 possible orientations for part building. To get the greatest coverage of decision space and the tangible effect on surface roughness, the layer thickness values are taken at minimum value $(0.1 \mathrm{~mm})$ and maximum value $(0.4 \mathrm{~mm})$ and in between like $(0.3 \mathrm{~mm})$. On the other hand, the building angles are taken from $0^{\circ}$ (vertical surface) to $80^{\circ}$ (just before the horizontal surface) in step of $10^{\circ}$.

\section{New 3D CAD Specimen}

In this experiment, it is needed to measure the roughness for each orientation (nine orientation angles) at each value of thee layer thicknesses that means it is required to build 27 specimens. The huge number of measurements and building specimens will increase the measurement error and cost that is why a new CAD specimen is designed (Fig. 2) to reduce the number of rebuilding specimens to three only.

\section{SURFACE ROUGHNESS ASSESSMENT}

The device used in the experiment was surtronic 3+ by Taylor Hobson precision company shown in Fig. 3. The cut off length (Lc) was $0.8 \mathrm{~mm}$ and the evaluation length (Ln) was $5 \mathrm{Lc}$, which equal to $4 \mathrm{~mm}$. The device was calibrated with the test piece to grantee the measured data. The surface parameter chosen to assessment the surface is Ra.

\section{Experimental Results}

The surface roughness $(\mathrm{Ra})$ for each surface angle at each layer thickness is measured. To ensure the precision of the measurements and coverage the surface area, there are three values of measurements in different position taken. After that, the average reading is calculated to evaluate the surface roughness. Table 2 shows the average value of the measurements for three levels of layer thickness. Figure 4 shows the nonlinear relationship between the surface orientation and the surface roughness at three different values of layer thickness.

\section{Polynomial Regression Model}

Polynomials are very flexible and useful where a model must be developed empirically. In the presented model, polynomial regression is used to fit a nonlinear 
relationship between the building orientation and the surface roughness at certain layer thickness.

The general form of the polynomial is:

$F(x)=a_{n-1} x^{n-1}+a_{n-2} x^{n-2}+\ldots+a_{2} x^{2}+a_{1} x+a_{0}$

where $n$ : is the number of measuring points, $F(x)$ : is surface angle $(O)$ and $x$ : is the surface roughness $(\mathrm{Ra})$, and $\mathrm{a}$ : is the coefficients of polynomial. The average values of roughness is taken at $O=10^{\circ}, 20^{\circ}, 40^{\circ}, 50^{\circ}, 70^{\circ}, 80^{\circ}$ and the remaining values at $\mathrm{O}=30^{\circ}, 60^{\circ}$ are used for the model verifications. To determine the polynomial order $(n)$, several attempts is done to calculate the maximum and minimum error between the actual and predicated values of surface angle at different order (n) are reported in Table 3.

The order $(n)$ of the following models is chosen based on the minimum error:

At layer thickness $=0.1 \mathrm{~mm}$

$\mathrm{O}=0.0447 R a^{5}-2.2535 R a^{4}+44.5902 R a^{3}-432.4396 R a^{2}+2068.2 R a-3.9136^{\star} 10^{3}$

\section{At layer thickness $=0.3 \mathrm{~mm}$}

$\mathrm{O}=4.8567^{*} 10^{-4} \mathrm{Ra}^{5}-0.065 \mathrm{Ra}^{4}+3.4226 \mathrm{Ra}^{3}-88.5514 \mathrm{Ra}^{2}+1.1328^{*} 10^{3} \mathrm{Ra}-5.7561^{\star} 10^{3}$

\section{At layer thickness $=0.4 \mathrm{~mm}$}

$\mathrm{O}=2.5323^{*} 10^{-6} R a^{5}-6.4117^{*} 10^{-4} R a^{4}+0.0638 R a^{3}-3.1085 R a^{2}+75.138 R a-692.3$

Figures 5, 6 and 7 show the error between the experimental measurements data and the predictions of the model. Tables 4, 5 and 6 list the differences between the model predictions and the corresponding actual measurements.

\section{Model Verification}

For verification, the models tested at $\mathrm{O}=30^{\circ}$ and $60^{\circ}$ at the three levels of layer thickness. The results represented in Table 7.

\section{CONCLUSION}

\section{Through this practical study and the obtained results, it can be concluding} that:

- The layer thickness increases the effect of building orientation on roughness value increases.

- The horizontal and vertical surfaces usually have better surface quality that is why the part should be oriented to make surfaces are horizontal or vertical as possible. 
- The early prediction of CAD model orientation is useful information to the designers in order to export the STL file in desired orientation to satisfy the required surface roughness. This will lead to save non-productive time, manufacturing trails, and building cost .

- The presented empirical models for desired surface roughness maximize the machine utilization and give the useful information to the FDM machine users to choose the process parameters.

- The models give the limits of surface roughness of the machine; which will allow the manufacturer to make the better decision to fabricate the part either on $\mathrm{CNC}$ or on $\mathrm{AM}$ machine to satisfy the product requirements.

\section{FUTURE WORK}

This work can be extended by creating an Artificial Neural Network (ANN) to choose the suitable layer thickness and building orientation to satisfy the desired surface roughness.

\section{REFERENCES}

[1] Anthony A. D'Amico, Analise Debaie, Amy M. Peterson, "Effect of layer thickness on irreversible thermal expansion and interlayer strength in fused deposition modeling", Rapid Prototyping Journal, Vol. 23 Issue: 5, pp.943-953 (2017).

[2] Huang SH, Liu P, Mokasdar A, and Hou L., "Additive manufacturing and its societal impact: a literature review", International Journal of Advanced Manufacturing Technology, Vol. 67(5-8), pp 1191-1203, (2013).

[3] Zhai YW, Lados DA, and Lagoy JL., "Additive manufacturing: making imagination the major limitation". JOM, 66(5), 808-816, (2014).

[4] Tim Femmer, Ina Flac, and Matthias Wessling, "Additive Manufacturing in Fluid Process Engineering", Chem. Ing. Tech. Vol. 88, No. 5, pp 535-552, (2016).

[5] Daekeon Ahn, Jin-Hwe Kweon, Soonman Kwon, Jungil Song, and Seokhee Lee. "Representation of surface roughness in fused deposition modeling", Vol. 209 (15-16), pp. 5593-5600, (2009).

[6] Hamoud M., EL-Wahab A.I., and Barakat A., " Speeding Up Algorithm For Building The STL Model Using 3D Printing" 17th International Conference On Applied Mechanics And Mechanical Engineering - AMME- pp 83-9717, Cairo, Egypt, April 19-21, (2016).

[7] Bethany C. Gross, Jayda L. Erkal, Sarah Y. Lockwood, Chengpeng Chen, and Dana M Spence, "An Evaluation of 3D Printing and its Potential Impact on Biotechnology and the Chemical Sciences", Vol. 86 (7), pp. 3240-3253. (2014). 
[8] Hamoud M. A., "Modeling And Optimization Of Rapid Prototyping", M.Sc. Thesis, Mechanical Engineering Dep., Faculty of Engineering, Helwan University, Egypt, (2008).

[9] K. Cooper, "Rapid Prototyping Technology: Selection and Application (Mechanical Engineering)", CRC Press, Boca Raton, FL (2001).

[10] Di Wang, Yang Liu and Yongqiang Yang, "Theoretical and experimental study on surface roughness of $316 \mathrm{~L}$ stainless steel metal parts obtained through selective laser melting", Rapid Prototyping Journal, Vol. 22/4 pp. 706-716, (2016).

[11] Ebrahim Vahabli and Sadegh Rahmati, "Hybrid estimation of surface roughness distribution in FDM parts using analytical modeling and empirical investigation", Int J Adv Manuf Technol, DOI 10.1007/s00170-016-8949-x, (2016).

[12] P. Delfs, M. Tows, and H.-J. Schmid, "Surface Roughness Optimized Alignment Of Parts For Additive Manufacturing Processes", 26th Annual International Solid Freeform Fabrication Symposium, Austin, August 10-12, (2015).

[13] Alberto Boschetto, Veronica Giordano and Francesco Veniali, "3D roughness profile model in fused deposition modelling" Rapid Prototyping Journal, Vol. 19 Iss 4, pp. $240-252$, (2013).

[14] P. E. Reeves, "Reducing the surface deviation of stereolithography using inprocess techniques," Rapid Prototyping Journal, Vol. 3, No. 1, pp. 20-31, (1997).

[15] P. B. Bacchewar, S. K. Singhal, and P. M. Pandey, "Statistical modelling and optimization of surface roughness in the selective laser sintering process," Proceedings of the Institution of Mechanical Engineers, Part B: Journal of Engineering Manufacture, Vol. 221, No. 1, pp. 35-52, (2007).

\section{Figures and Tables}

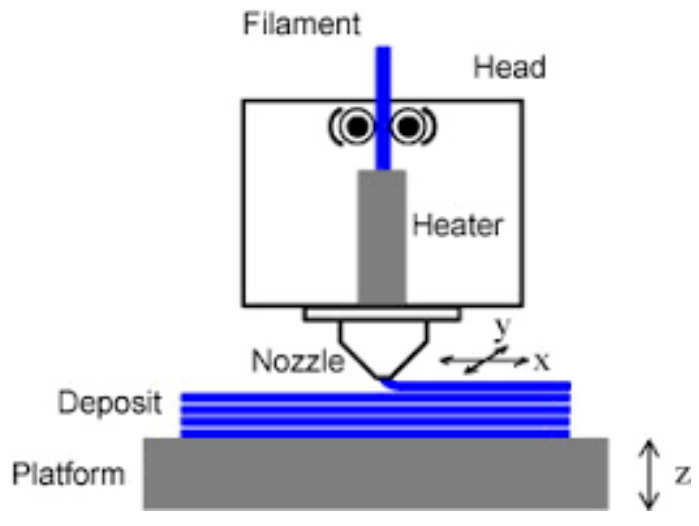

Fig.1. Fused deposition modeling.

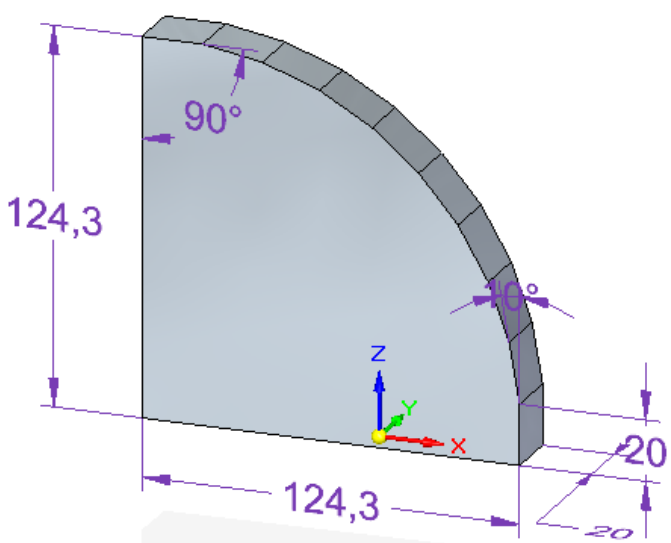

Fig.2. CAD model of the designed specimen 


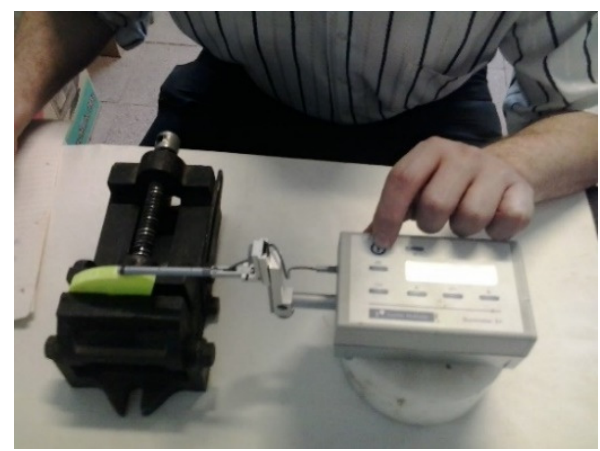

Fig.3. Experiment setup using surtronic +3 .

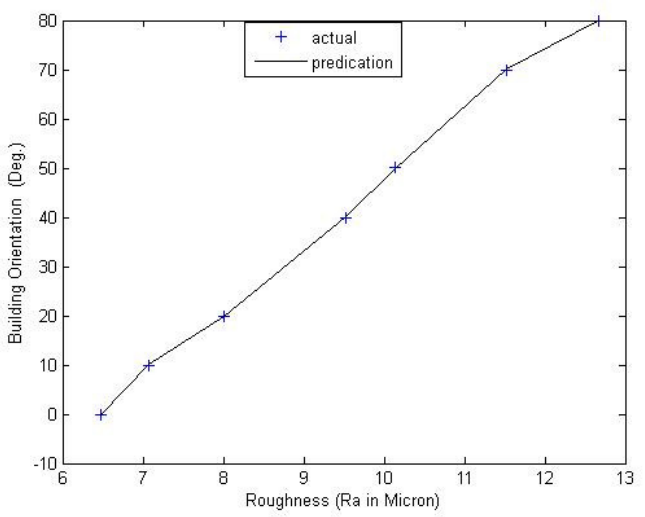

Fig.5. Predictive model at layer thickness $=0.1 \mathrm{~mm}$.

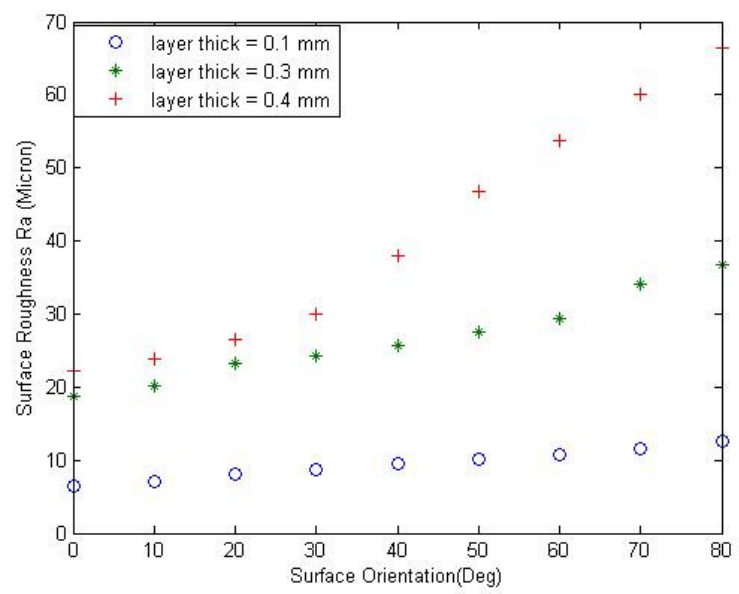

Fig.4. Effect of the building orientation on the surface roughness.

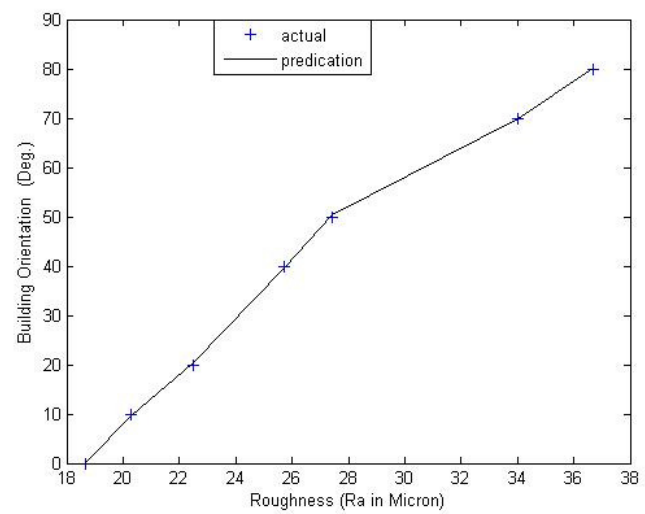

Fig.6. Predictive model at layer thickness $=$ $0.3 \mathrm{~mm}$.

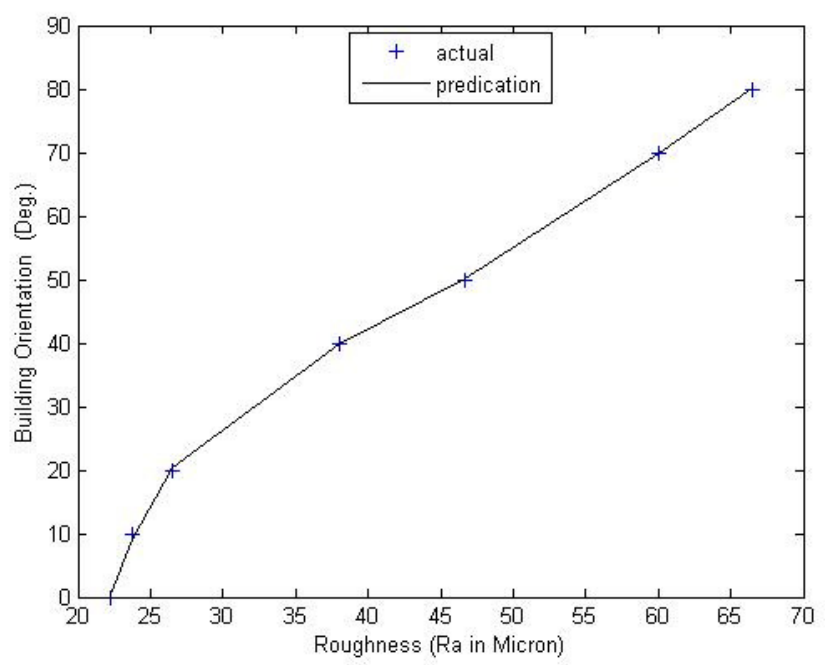

Fig.7. Predictive model at layer thickness $=0.4 \mathrm{~mm}$. 
Table 1. Technical specifications of the AM machine.

\begin{tabular}{|c|c|}
\hline $\begin{array}{c}\text { Print Technology } \\
\text { envelope }\end{array}$ & FDM \\
\hline $\begin{array}{c}\text { Muilding } \\
\text { thimum layer } \\
\text { thickness }\end{array}$ & 100 microns $15.5 \mathrm{~cm}$ \\
\hline $\begin{array}{c}\text { Filament } \\
\text { diameter }\end{array}$ & $1.75 \mathrm{~mm}$ \\
\hline $\begin{array}{c}\text { Filament } \\
\text { material }\end{array}$ & $\mathrm{ABS}$ \\
\hline Nozzle diameter & $0.4 \mathrm{~mm}$ \\
\hline CAD extensions & STL, obj, thing \\
\hline Connectivity & USB, SD card \\
\hline
\end{tabular}

Table 2. The average values of $\mathrm{Ra}$ (micron) at different layer thickness.

\begin{tabular}{|c|c|c|c|}
\hline \multirow{2}{*}{$\begin{array}{l}\text { Surface } \\
\text { angle (0) } \\
\text { in } \\
\text { degree(s) }\end{array}$} & \multicolumn{3}{|c|}{$\begin{array}{l}\text { Layer thickness } \\
\qquad(\mathrm{mm})\end{array}$} \\
\hline & 0.1 & 0.3 & 0.4 \\
\hline 0 & 6.47 & 18.67 & 22.27 \\
\hline 10 & 7.07 & 20.3 & 23.8 \\
\hline 20 & 8 & 22.5 & 26.5 \\
\hline 30 & 8.85 & 24.2 & 30 \\
\hline 40 & 9.53 & 25.73 & 38 \\
\hline 50 & 10.13 & 27.43 & 46.7 \\
\hline 60 & 10.77 & 29.3 & 53.8 \\
\hline 70 & 11.53 & 34 & 60.07 \\
\hline 80 & 12.67 & 36.7 & 66.47 \\
\hline
\end{tabular}

Table 3. The Max. and Min. error at different values of polynomial order (n).

\begin{tabular}{|c|c|c|c|c|c|c|}
\hline \multirow{2}{*}{ Lt } & \multirow{2}{*}{ Error } & \multicolumn{5}{|c|}{ Polynomial order (n) } \\
\cline { 3 - 7 } & & $\mathbf{1}$ & $\mathbf{2}$ & $\mathbf{3}$ & $\mathbf{4}$ & $\mathbf{5}$ \\
\hline \multirow{2}{*}{0.1} & Min & 0.859 & 0.217 & 0.046 & 0.088 & 0.003 \\
\cline { 3 - 7 } & Max & 0.114 & 2.658 & 1.966 & 0.756 & 0.114 \\
\hline \multirow{2}{*}{0.3} & Min & 1.074 & 0.322 & 0.357 & 0.119 & 0.008 \\
\cline { 3 - 7 } & Max & 7.229 & 2.665 & 2.574 & 1.708 & 0.47 \\
\hline \multirow{2}{*}{0.4} & Min & 0.521 & 1.118 & 1.14 & 0.105 & 0.006 \\
\cline { 2 - 6 } & Max & 7.958 & 5.371 & 2.99 & 1.104 & 0.805 \\
\hline
\end{tabular}


Table 4. The differences between the measured values and the predictive values at layer thickness $=0.1 \mathrm{~mm}$.

\begin{tabular}{|c|c|c|c|}
\hline $\begin{array}{c}\text { Measured } \\
\text { roughness } \\
\text { Ra (micron) }\end{array}$ & $\begin{array}{c}\text { Designed } \\
\text { orientation } \\
\text { (Deg.) }\end{array}$ & $\begin{array}{c}\text { Predicative } \\
\text { orientation }\end{array}$ & $\begin{array}{c}\text { Absolute error } \\
\text { (micron) }\end{array}$ \\
\hline 6.47 & 0 & -0.015 & 0.015 \\
\hline 7.07 & 10 & 10.047 & 0.047 \\
\hline 8 & 20 & 19.935 & 0.065 \\
\hline 9.53 & 40 & 40.114 & 0.114 \\
\hline 10.13 & 50 & 49.903 & 0.097 \\
\hline 11.53 & 70 & 70.019 & 0.019 \\
\hline 12.67 & 80 & 79.997 & 0.003 \\
\hline
\end{tabular}

Table 5. The differences between the measured values and the predictive values at layer thickness $=0.3 \mathrm{~mm}$

\begin{tabular}{|c|c|c|c|}
\hline $\begin{array}{c}\text { Measured } \\
\text { roughness } \\
\text { (micron) }\end{array}$ & $\begin{array}{c}\text { Designed } \\
\text { orientation } \\
\text { (Deg.) }\end{array}$ & $\begin{array}{c}\text { Predicative } \\
\text { orientation }\end{array}$ & $\begin{array}{c}\text { Absolute } \\
\text { error (micron) }\end{array}$ \\
\hline 18.67 & 0 & 0.084 & 0.084 \\
\hline 20.3 & 10 & 9.712 & 0.288 \\
\hline 22.5 & 20 & 20.409 & 0.409 \\
\hline 25.73 & 40 & 39.53 & 0.47 \\
\hline 27.43 & 50 & 50.281 & 0.281 \\
\hline 34 & 70 & 69.975 & 0.025 \\
\hline 36.7 & 80 & 80.008 & 0.008 \\
\hline
\end{tabular}


Table 6. The differences between the measured values and the predictive values at layer thickness $=0.4 \mathrm{~mm}$.

\begin{tabular}{|c|c|c|c|}
\hline $\begin{array}{c}\text { Ra } \\
\text { (micron) }\end{array}$ & $\begin{array}{c}\text { Designed } \\
\text { orientation } \\
\text { (Deg.) }\end{array}$ & $\begin{array}{c}\text { Predicative } \\
\text { orientation }\end{array}$ & $\begin{array}{c}\text { Absolute } \\
\text { error (micron) }\end{array}$ \\
\hline 22.27 & 0 & 0.403 & 0.403 \\
\hline 23.8 & 10 & 9.195 & 0.805 \\
\hline 26.5 & 20 & 20.47 & 0.47 \\
\hline 38 & 40 & 39.881 & 0.119 \\
\hline 46.7 & 50 & 50.064 & 0.064 \\
\hline 60.07 & 70 & 69.981 & 0.019 \\
\hline 66.47 & 80 & 80.006 & 0.006 \\
\hline
\end{tabular}

Table 7: Model verification results.

\begin{tabular}{|c|c|c|c|c|}
\hline $\begin{array}{c}\text { Lt } \\
(\mathbf{m m})\end{array}$ & $\begin{array}{c}\text { Desired } \\
\text { Ra }\end{array}$ & $\begin{array}{c}\text { Predicted } \\
\text { orient } \\
\text { (deg.) }\end{array}$ & $\begin{array}{c}\text { Measured } \\
\text { orient. } \\
\text { (deg.) }\end{array}$ & Error \\
\hline \multirow{2}{*}{0.1} & 8.85 & 29.92 & 30 & 0.08 \\
\cline { 2 - 5 } & 10.77 & 60.02 & 60 & 0.02 \\
\hline \multirow{2}{*}{0.3} & 24.2 & 29.9 & 30 & 0.1 \\
\cline { 2 - 5 } & 29.3 & 60.2 & 60 & 0.2 \\
\hline \multirow{2}{*}{0.4} & 30 & 29.5 & 30 & 0.5 \\
\cline { 2 - 5 } & 60.5 & 60.5 & 60 & 0.5 \\
\hline
\end{tabular}

